\title{
Gene Expression Profiles in Peripheral Blood Mononuclear Cells of Asian Obstructive Sleep Apnea Patients
}

\author{
Shih-Wei Lin ${ }^{1,2}$, Chi-Neu Tsai ${ }^{1,3}$, Yun-Shien Lee ${ }^{3,4}$, Shu-Fen $\mathrm{Chu}^{2}$, Ning-Hung Chen ${ }^{2,5}$
}

Background: Obstructive sleep apnea (OSA) syndrome is a complicated disease involving several pathogenic mechanisms. Microarray technology provides a high-throughput means of identifying differentially expressed genes in patients with OSA.

Methods: An Affymetrix U133A gene chip was used to globally analyze the transcriptome of peripheral blood mononuclear cells (PBMC) in patients with OSA and nonapneic control participants after overnight polysomnography.

Results: $\quad$ Several genes were differentially expressed in patients with OSA compared with control participants. These genes included disintegrin and metalloproteinase domain 29 (ADAM29), solute carrier family 18 (vesicular acetylcholine) member 3 (SLC18A3), cyclin-dependent kinase inhibitor $2 \mathrm{C}(C D K N 2 C)$, and fibronectin-like domain-containing leucine-rich transmembrane protein 2 (FLRT2). Among these genes, the expression levels of ADAM29 ( $p=0.00003)$, FLRT2 $(p<0.0001)$, and $S L C 18 A 3(p=0.0006)$ were found to be possible markers of severe OSA [respiratory disturbance index $(\mathrm{RDI})>30$ ].

\begin{abstract}
At a Glance Commentary
Scientific background of the subject

Obstructive sleep apnea syndrome is a complicated disease involving several pathogenic mechanisms. Asian patients with OSA are different from other ethnic populations in obesity and craniofacial factors, thus potential different pathogenic mechanisms. Microarray technology may provide a high-throughput means of identifying differentially expressed genes in Asian patients with OSA.

\section{What this study adds to the field}

This study showed that PBMC expression of ADAM29, FLRT2, and SLC18A3 could be assessed as part of a routine screen to help identify individuals at risk of severe OSA in Asian populations.
\end{abstract}

Conclusion: Our data suggest that PBMC expression of ADAM29, FLRT2, and SLC18A3 could be assessed as part of a routine screen to help identify individuals at risk of severe OSA in Asian populations. (Biomed J 2014;37:60-70)

Key words: affymetrix U133A chip, Asian population, gene expression profile, genetic markers, obstructive sleep apnea, signaling pathways

$\mathrm{O}^{\mathrm{s}}$ bstructive sleep apnea (OSA) syndrome is characterized by episodes of complete or partial pharyngeal obstruction during sleep, together with symptoms of daytime sleepiness or frequently altered cardiopulmonary function. ${ }^{[1]}$ Epidemiologic studies have shown that this disease affects $2-4 \%$ of middle-aged adults; however, only a small proportion of these individuals have been clinically diagnosed because of a lack of awareness of the existence of sleep apnea. ${ }^{[2]}$ This is a point of concern as patients with OSA tend to have an increased risk of diurnal hypertension, nocturnal dysrhythmias, pulmonary hypertension, right and left ventricular failure, myocardial infarction, and stroke. ${ }^{[3-7]}$ In addition, patients with OSA have an increased risk of motor vehicle accidents (at least sevenfold greater than normal), which strongly suggests that sleep apnea affects not only the patient's quality of life but also the safety of the general public. ${ }^{[8-10]}$

From the ${ }^{1}$ Graduate Institute of Clinical Medical Sciences, College of Medicine, Chang Gung University, Taoyuan, Taiwan; ${ }^{2}$ Department of Pulmonary Medicine, Sleep Center, Chang Gung Memorial Hospital at Linkou, Chang Gung University College of Medicine, Taoyuan, Taiwan; ${ }^{3}$ Genomic Medicine Research Core Laboratory (GMRCL), Chang Gung Memorial Hospital at Linkou, Chang Gung University College of Medicine, Taoyuan, Taiwan; ${ }^{4}$ Department of Biotechnology, Ming-Chua University, Taoyuan, Taiwan; ${ }^{5}$ Chang Gung Institute of Technology, Taoyuan, Taiwan

Received: Apr. 18, 2012; Accepted: Mar. 21, 2013

Correspondence to: Dr. Ning-Hung Chen, Department of Pulmonary Medicine, Sleep Center, Chang Gung Memorial Hospital at Linkou. 5, Fusing St., Gueishan, Taoyuan 333, Taiwan (R.O.C.). Tel: 886-3-3281200; ext. 2281; Fax: 886-3-3287787; E-mail: nhchen@cgmh.org.tw

DOI: $10.4103 / 2319-4170.113188$ 
The severity of OSA is determined based on assessments of nasal flow, specifically the number of episodes of apnea and hypopnea per hour. The degree of hypoxic stress resulting from OSA can also be determined by examining changes in arterial oxygen desaturation during sleep. A full night of polysomnography (PSG), conducted by a technologist in a sleep laboratory, has traditionally been regarded as the gold standard for diagnosing sleep apnea. PSG is performed to confirm the presence of upper airway closure during sleep and to assess the patient's level of risk. ${ }^{[1]}$ The severity of sleep apnea is indicated by the number of episodes of apnea and hypopnea per hour of sleep [the apnea hypopnea in$\operatorname{dex}(\mathrm{AHI})]$ or the respiratory disturbance index (RDI). Most patients with sleep apnea have an RDI $>5 .^{[12]}$

Several factors have been reported to be associated with the pathogenesis of OSA, including age, sex, obesity, craniofacial structure, alcohol and other drug use, and ethnicity. ${ }^{[2,13-18]}$ Recent evidence suggests that ethnic factors also play another role in the pathogenesis of OSA, although sex and craniomandibular factors also contribute to OSA syndrome. In far eastern Asia, patients with OSA are less obese, but have a higher risk of developing severe OSA than Caucasians. ${ }^{[19]}$ Therefore, obesity might be a less significant risk factor for OSA in Asia given that most Asian patients with OSA are less obese than their Caucasians counterparts. ${ }^{[20]}$ Besides ethnic factors, chronically elevated proinflammatory mediators have been detected in patients with OSA. ${ }^{[21,22]}$ It has been postulated that cardiovascular complications are related to the inflammatory process induced by activation of proinflammatory mediators. ${ }^{[23]}$ Selectively activated inflammatory pathways [e.g., the transcription factor nuclear factor kappa B (NF B) pathway] contribute to endothelial dysfunction and cardiovascular disease. ${ }^{[24-27]}$ Taken together, the results of these studies indicate that OSA is a complicated disease involving several pathogenic mechanisms.

Microarray technology provides a high-throughput means of identifying differentially expressed genes, and thus potential pathogenic mechanisms, in patients with OSA. Differential expression of genes was found in studies using peripheral blood mononuclear cell (PBMC) samples from patients with OSA and non-obese children with OSA using the Affymetrix U133A chip. ${ }^{[28,29]}$ In these studies, several candidate genes were identified, including heme oxygenase 1 , superoxide dismutase 1 and 2 , and catalase. The identification of these genes implicated the activation of several mechanisms to modulate and adapt to increased reactive oxygen species (ROS) generated as a consequence of the frequent episodes of intermittent hypoxia/reoxygenation in patients with OSA. ${ }^{[28]}$ Patients in the aforementioned study had a mean body mass index (BMI) of $35.5 \pm 1.29 \mathrm{~kg} / \mathrm{m}^{2}$. Asian patients with OSA have lower BMI, but severe RDI. ${ }^{[18]}$
Therefore, we used the Affymetrix U133A gene chip to globally analyze differential transcriptome expression in PBMC samples from Asian patients with OSA and nonapneic control participants. Peripheral blood from patients with OSA $(n=6)$ or controls $(n=3)$ was collected for use as the training set after overnight PSG. The gene expression profile was analyzed using the Affymetrix U133A gene chip. We enrolled a further 25 patients with OSA and 24 control participants without apnea as a validation set to verify microarray data using real-time polymerase chain reaction (PCR). The gene signature, involved pathways, and possible markers of OSA were determined and are discussed in this report.

\section{METHODS}

\section{Patients and control participants}

Both patients and control participants were recruited from the Sleep Center of Chang Gung Memorial Hospital (CGMH). Full PSG monitoring was performed using a Somnologica Sleep System (Medicare, Reykjavík, Iceland) with simultaneous EEG, electro-oculography, electromyography, and ECG. Surface electrodes were used to record two channels of EEG (C3A2, C4A1), right and left electro-oculography, and submental electromyography. Ventilatory flow at the nose and mouth was measured with thermistors. Ventilatory movements of the chest and abdomen were monitored using inductive plethysmography bands. Arterial oxygen saturation $\left(\mathrm{SaO}_{2}\right)$ was measured transcutaneously using fingertip pulse oximetry. Apnea was defined as continuous cessation of airflow for $10 \mathrm{~s}$, whereas hypopnea was defined as a reduction in airflow for $10 \mathrm{~s}$ with oxygen desaturation $4 \%$, or an EEG arousal from sleep. Apneas were classified as obstructive, mixed, or central according to the diagnostic criteria of the American Academy of Sleep Medicine ${ }^{[1]}$ The RDI was determined by dividing the number of respiratory events by the estimated hours of sleep. PSG was performed from 10 p.m. to 6 a.m.

Inclusion criteria were: age from 18 to 75 years, RDI $>5$, and normal health in the week before the study. Control participants without apnea were recruited from participants who were referred for PSG monitoring because of other sleep problems. These participants had an RDI $<5$ and did not exhibit snoring as a primary symptom. Individuals who had systemic infections at the time of the study or within 2 weeks before the study were excluded.

The study protocol was approved by the Ethical Review Committee of CGMH, and written informed consent was obtained from all participants.

\section{RNA extraction}

Blood samples were collected at 6 a.m. after PSG and overnight fasting. All samples were stored in PAXgene RNA 
Blood Tubes for $4 \mathrm{~h}$ before RNA extraction. Extraction of total RNA was performed in accordance with the manufacturer's instruction (PAXgene Blood RNA System, PreAnalytiX, Hombrechtikon, Switzerland). The quality and quantity of RNA was analyzed using a Bioanalyzer 2100 (Agilent, Palo Alto, CA, USA). Gene expression profiles were analyzed using a human U133A GeneChip following the manufacturer's instructions (Affymetrix, Santa Clara, CA, USA).

\section{Microarray data processing}

Total RNA $(1 \mu \mathrm{g})$ isolated from peripheral blood was converted to cRNA using SuperScript II reverse transcriptase (Invitrogen, Carlsbad, CA, USA), and $25 \mu \mathrm{g}$ of labeled probe was hybridized to Affymetrix U133A arrays. Gene expression data were generated and normalized using the robust multichip average method ${ }^{[30]}$ with RMAEXPRESS (http:// stat-www.berkeley.edu/ bolstad/RMAExpress/RMAExpress. $\mathrm{html})$. The differential expression of genes between patients with OSA and control participants was selected with the fold-change $>2$ and $p<0.05$ (Mann-Whitney U test). A total of 56 genes were selected and hierarchical cluster analysis was performed. Gene cluster 3.0 and Treeview ${ }^{[31]}$ (bonsai.ims.u-tokyo.ac.jp/ mdehoon/software/cluster/), with average-linkage clustering algorithms, were used for visualization. In the resulting expression map, increased gene expression was indicated by red color, whereas decreased gene expression was indicated by green color. Black color indicated that expression was the same in patients with OSA and control participants [Figure 1].

\section{Pathway prediction analysis}

Network analyses of differentially expressed genes were performed using MetaCore Analytical Suite (GeneGo Inc., St. Joseph, MI, USA, http://www.genego.com). ${ }^{[32,33]}$ MetaCore is a web-based computational platform designed for systems biology and drug discovery. It includes a curate database of human protein interactions and metabolism; thus, it is useful for analyzing a cluster of genes in the context of regulatory networks and signaling pathways. For the network analysis of a group of genes, MetaCore can be used to calculate the statistical significance ( $p$ value) based on the probability of assembly from a random set of nodes (genes) of the same size as the input list. ${ }^{[33]}$ The 56 differentially expressed genes between patients with OSA and control participants were entered in to MetaCore analysis on the basis of Dijkstra's "shortest path" algorithm. A $p$ value was calculated ranking the pathways according to saturation with the objects from the differential gene list.

\section{Real-time reverse transcriptase polymerase chain reaction}

A total of $1 \mu \mathrm{g}$ of amplified anti-sense RNA (aRNA) (pre-treated with DNase) was mixed with reverse transcriptase (Roche, Mannheim, Germany) and oligo-dT primers to generate $25 \mathrm{~mL}$ of first strand cDNA. Real-time quantitative (RTQ)-PCR was performed using $0.5 \mu \mathrm{L}$ of the first strand cDNA synthesis mixture as a template with TaqMan primer/probe sets (Assay-on-Demand, Applied Biosystems, Foster City, CA, USA). The total reaction volume was $10 \mu \mathrm{L}$. Each reaction was carried out in triplicate on 384 well plates. Relative gene expression was calculated using the comparative CT method. Glyceraldehyde 3 phosphate dehydrogenase (GAPDH) was used as the internal control.

\section{Statistical analysis}

Continuous variables were compared between patients with OSA and control participants using Mann-Whitney test. Unconditional logistic regression analysis was per-

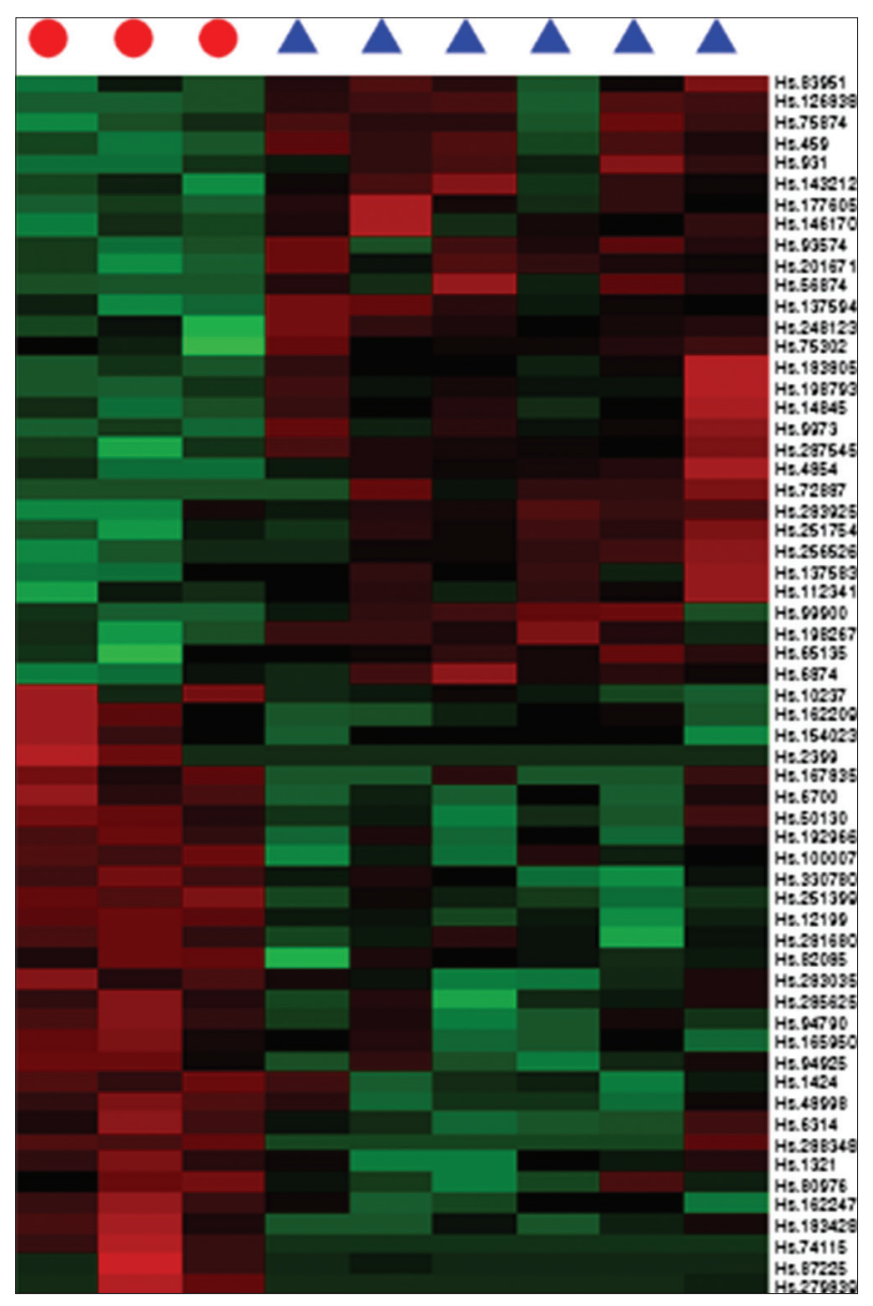

Figure 1: Differential expression profiles in OSA and controls analyzed by hierarchical clustering. In the hierarchical clustering of relative change in gene expression using a probe set of 56 filtered genes (gene vector $>0.5 \mathrm{SD}$ ), red indicates up-regulation and green indicates down-regulation in the gene expression of OSA patients (blue triangle: $\boldsymbol{\Delta}$ ) as compared with three normal controls (red circular: $\bullet$ ) 
formed to calculate odds ratios (ORs) and 95\% confidence intervals (CIs), with adjustment for possible confounders (sex as a nominal variable and age as a continuous variable). All analyses were performed using Statistical Analysis Software for Windows, version 8.12 (SAS Institute, Cary, NC, USA).

\section{RESULTS}

Samples from six patients with OSA and three nonapneic control participants were chosen for microarray analysis and the corresponding data were used as the training set. The demographic characteristics of these participants are summarized in Table 1. The mean BMI of patients with OSA and control participants was $25.2 \pm 4.7 \mathrm{~kg} / \mathrm{m}^{2}$ and $20.8 \pm 2.0 \mathrm{~kg} / \mathrm{m}^{2}$, respectively. Three patients with OSA (OSA1, OSA3, and OSA5) had a BMI of less than $25 \mathrm{~kg} / \mathrm{m}^{2}$. The mean RDI of the patients with OSA was $42.9 \pm 28.9$.

Of the 14,210 genes assessed, the expression of 343 was found to be significantly different in PBMCs between patients with OSA and nonapneic control participants (data not shown). The threshold of significance was taken as a twofold up- or down-regulation because a previous study demonstrated that changes in PBMC gene expression in peripheral blood are generally minor, except those in response to infectious diseases. ${ }^{[34]}$ The differentially expressed genes were categorized using Gene-Ontology; 76, 53, and 47 genes were identified to be involved in biological processes, cellular components, and molecular function, respectively [Table 2]. The four most differentially expressed processes in the category of biological processes in patients with OSA involved cellular physiological processes (17 up-regulated genes and 7 down-regulated genes), metabolism, cell communication, and response to stimuli [Table 2]. Interestingly, in categorizing these differential expressed genes by their molecular functions, we found that hydrolase activity, nucle-

Table 1: Demographic data for participants in the training set: Samples from these participants were used for the affymetrix microarray (U133A chip)

\begin{tabular}{lccccccc}
\hline Variable & Sex & Age & BMI & RDI & DI & $\begin{array}{c}\text { Mini } \\
\mathrm{SaO}_{2}(\%)\end{array}$ & $\begin{array}{c}\text { Mean } \\
\mathrm{SaO}_{2}(\%)\end{array}$ \\
\hline OSA1 & $\mathrm{M}$ & 54 & 19.8 & 31.3 & 0.2 & 90.1 & 97.7 \\
OSA2 & $\mathrm{M}$ & 44 & 27.4 & 57.9 & 47.3 & 69.0 & 92.3 \\
OSA3 & $\mathrm{M}$ & 75 & 21.1 & 39.0 & 27.4 & 80.5 & 96.9 \\
OSA4 & $\mathrm{M}$ & 46 & 25.0 & 69.0 & 41.3 & 79.1 & 96.8 \\
OSA5 & $\mathrm{F}$ & 67 & 24.7 & 34.7 & 16.0 & 84.0 & 93.3 \\
OSA6 & $\mathrm{M}$ & 40 & 33.0 & 107.6 & 40.6 & 77.4 & 92.8 \\
Control 1 & $\mathrm{F}$ & 68 & 18.5 & 0 & 0 & 99.0 & 99.0 \\
Control 2 & $\mathrm{M}$ & 42 & 22.1 & 1.5 & 0 & 94.3 & 97.6 \\
Control 3 & $\mathrm{M}$ & 37 & 21.9 & 0 & 0 & 97.0 & 99.0 \\
\hline Abbrity
\end{tabular}

Abbreviations: OSA: Obstructive sleep apnea; BMI: Body mass index; RDI: Respiratory disturbance index; DI: Desaturation index
Table 2: Differentially expressed genes in patients with OSA categorized by gene ontology

\begin{tabular}{|c|c|c|}
\hline \multirow[t]{2}{*}{ Category } & \multicolumn{2}{|c|}{ Number of genes } \\
\hline & Up-regulated & Down-regulated \\
\hline \multicolumn{3}{|l|}{ Biological process } \\
\hline Reproduction & 1 & \\
\hline Cell communication & 8 & 4 \\
\hline Metabolism & 11 & 6 \\
\hline Morphogenesis & 6 & 1 \\
\hline Death & 2 & \\
\hline Reproductive behavior & 2 & \\
\hline Homeostasis & & 1 \\
\hline Secretion & & 2 \\
\hline Organ development & 2 & \\
\hline $\begin{array}{l}\text { Positive regulation of biological } \\
\text { process }\end{array}$ & 2 & \\
\hline $\begin{array}{l}\text { Negative regulation of biological } \\
\text { process }\end{array}$ & 1 & 1 \\
\hline Regulation of physiological process & 5 & 3 \\
\hline Regulation of cellular process & 5 & 2 \\
\hline Coagulation & & 2 \\
\hline Organismal physiological process & 7 & 5 \\
\hline Cellular physiological process & 17 & 7 \\
\hline Response to stimulus & 6 & 4 \\
\hline Localization & 1 & 2 \\
\hline \multicolumn{3}{|l|}{ Cellular component } \\
\hline Cell fraction & 3 & \\
\hline Nucleosome & 1 & \\
\hline Extracellular matrix & 3 & 2 \\
\hline Intracellular & 13 & 3 \\
\hline $\begin{array}{l}\text { Dystrophin-associated glycoprotein } \\
\text { complex }\end{array}$ & & 1 \\
\hline Membrane & 8 & 8 \\
\hline Membrane-bound organelle & 7 & 2 \\
\hline Non-membrane-bound organelle & 6 & 1 \\
\hline Intracellular organelle & 12 & 3 \\
\hline Organelle lumen & 1 & \\
\hline \multicolumn{3}{|l|}{ Molecular function } \\
\hline Microfilament motor activity & 1 & \\
\hline Nucleotide binding & 2 & 1 \\
\hline Pattern binding & 1 & \\
\hline Nucleic acid binding & 4 & 2 \\
\hline Transcription factor activity & 3 & 1 \\
\hline $\begin{array}{l}\text { RNA polymerase II transcription } \\
\text { factor activity }\end{array}$ & & 1 \\
\hline Enzyme inhibitor activity & 5 & 1 \\
\hline Receptor activity & 4 & 3 \\
\hline $\begin{array}{l}\text { Structural constituent of } \\
\text { cytoskeleton }\end{array}$ & 1 & \\
\hline $\begin{array}{l}\text { Extracellular matrix structural } \\
\text { constituent }\end{array}$ & 1 & \\
\hline Amine transporter activity & 1 & \\
\hline $\begin{array}{l}\text { Neurotransmitter transporter } \\
\text { activity }\end{array}$ & 1 & \\
\hline Electron transporter activity & 1 & 1 \\
\hline
\end{tabular}


Table 2: Contd...

\begin{tabular}{lcc}
\hline Category & \multicolumn{2}{c}{ Number of genes } \\
\cline { 2 - 3 } & Up-regulated & Down-regulated \\
\hline Bacterial binding & 1 & \\
Oxidoreductase activity & 2 & 1 \\
Transferase activity & 1 & 3 \\
Hydrolase activity & 6 & 1 \\
Isomerase activity & & \\
Kinase regulator activity & 1 & \\
Carbohydrate binding & 1 & 1 \\
Peptide binding & 2 & \\
Ion binding & 1 & \\
\hline
\end{tabular}

Abbreviation: OSA: Obstructive sleep apnea

ic acid binding, protein binding, enzyme inhibitor activity, and receptor activity were differentially altered [Table 2]. This suggests that global transcripts and protein expression changed in PBMCs from patients with OSA.

To further systematically analyze these differentially expressed genes using MetaCore (GeneGo, St Joseph, MI, USA), 56 genes (with $>2$-fold changes and $p<0.05$ ) were categorized into 19 known or probable functional pathways [Table 3]. Among these pathways, several intracellular signaling cascades were identified that may be involved in the pathogenesis of OSA, including G-protein coupled receptor signaling pathways, transforming growth factor- $\beta$ (TGF- $\beta$ ) receptor signaling pathways, and cell surface linked signal transduction pathways [Table 3]. Expression of genes in pathways involving chromatin remodeling [Table 3] was also altered in patients with OSA, suggesting that global transcriptome alterations in PBMCs might be due to global epigenetic modifications [Table 3]. Expression of genes in other pathways involved in cell adhesion, DNA replication, and positive regulation of $\mathrm{T}$ cell activation was also found to be altered in patients with OSA [Table 3].

After performing global analysis to identify the functional pathways potentially involved in OSA pathogenesis, we examined whether the identified differentially expressed genes could be used as markers of OSA in Asian patients. As illustrated in Figure 1 and Table 4, several of the top 30 genes identified to have altered regulation were not previously found to be associated with OSA, particularly in the PBMC transcriptome. A disintegrin and metalloproteinase domain 29 (ADAM29) and immunoglobulin superfamily, member 2 (IGSF2) were the most significantly up-regulated (7.6-fold) and down-regulated (fourfold) genes in patients with OSA compared with control participants.

To confirm the microarray data in this training set, the expression levels of six genes were analyzed using RTQ-PCR (the candidate genes were determined on the basis of the fold change). The expression levels of ADAM29, fibronectin-like domain-containing leucine-rich transmembrane protein 2 (FLRT2), solute carrier family 18 (vesicular acetylcholine) member 3 (SLC18A3), cyclin-dependent kinase inhibitor $2 \mathrm{C}(C D K N 2 C)$, and matrix metallopeptidase 14 (membrane-inserted) (MMP14) were consistent with the microarray data, whereas the expression of peroxisomal trans-2-enoyl-CoA reductase (HSA250303) was not obviously decreased as determined by real-time PCR [Table 5].

To further confirm the microarray data, 25 patients with OSA and 24 nonapneic control participants were used as a validation set to analyze expression of these six genes. The mean age of the nonapneic control participants was $32.8 \pm 11.3$ years (range: $21-63$ years), whereas the mean age of the patients with OSA was $44.8 \pm 9.8$ years (range: 32-69 years) [Table 6]. The mean BMI was $21.8 \pm 2.2 \mathrm{~kg} / \mathrm{m}^{2}$ for control participants and $26.5 \pm 3.5 \mathrm{~kg} / \mathrm{m}^{2}$ for patients with OSA $(p<0.001)$, whereas the corresponding mean RDI was $0.6 \pm 0.9$ and $41.9 \pm 26.7$, respectively $(p<0.001)$ [Table 6]. The comparison between participants in the training set and the validation set is shown in Table 7. As shown in Figure 2, the expression levels of ADAM29 $(p=0.0003)$, SLC18A3 $(p=0.0006)$, and FLRT2 $(p<0.0001)$ were significantly different between patients with severe OSA (RDI 30) and patients with mild OSA and control participants (RDI $<30)$. There were no differences in the expression levels of ADAM29 and SLC18A3 between patients with mild OSA and control participants ( $p=0.62$ and 0.10 , respectively). The different FLRT2 expression levels between mild OSA and control subjects was borderline significant $(p=0.046)$. Expression of $C D K N 2 C$ was significantly different between patients with mild OSA and control participants $(p=0.01)$; however, there was no difference between patients with severe OSA and control participants $(p=0.064)$. There were no significant differences in expression of HSA250303 ( $p=0.45)$ or MMP14 $(p=0.064)$ in the validation set [Figure 2]. Our data show that there were significant differences in the expression of three genes (ADAM29, SLC18A3, and FLRT2) between patients with severe OSA $(\mathrm{RDI}<30)$ and patients with mild OSA and control participants.

\section{DISCUSSION}

In this study, we firstly characterized the global gene expression profile in peripheral blood obtained from Asian adults with OSA. Our results suggest that genes involving in cell adhesion, cell communication, and receptor signaling are differentially expressed in patients with severe OSA compared with nonapneic control individuals. The specific genes found to be differentially expressed were ADAM29, FLRT2, and SLC18A3.

ADAM29 has been cloned and mapped to human chromosome 4. Findings from a previous study revealed that ADAM29 was highly expressed in testis, but only slightly or not at all expressed in the other 15 human tissues tested using 
Table 3: Functional pathways involved in OSA pathogenesis as predicted by the MetaCore web-based program

\begin{tabular}{|c|c|c|}
\hline Process & Size & Target \\
\hline $\begin{array}{l}\text { Cellular component organization and biogenesis }(77.5 \% ; 6.331 \mathrm{e}-12) \text {, chromatin remodeling }(22.5 \% ; 1.759 \mathrm{e}-11) \text {, } \\
\text { chromatin-mediated maintenance of transcription }(10.0 \% ; 1.976 \mathrm{e}-09) \text {, chromatin modification }(22.5 \% ; 2.748 \mathrm{e}-09) \text {, positive } \\
\text { regulation of gene expression, epigenetic }(10.0 \% ; 5.910 \mathrm{e}-09)\end{array}$ & 50 & 14 \\
\hline $\begin{array}{l}\text { Extracellular matrix organization and biogenesis }(14.9 \% ; 4.407 \mathrm{e}-08) \text {, cell surface receptor linked signal transduction } \\
(46.8 \% ; 4.645 \mathrm{e}-08) \text {, Smad protein nuclear translocation }(8.5 \% ; 5.333 \mathrm{e}-08) \text {, transforming growth factor beta receptor signaling } \\
\text { pathway }(14.9 \% ; 6.095 \mathrm{e}-08) \text {, transmembrane receptor protein serine/threonine kinase signaling pathway }(14.9 \% ; 6.908 \mathrm{e}-07)\end{array}$ & 50 & 13 \\
\hline $\begin{array}{l}\text { Proteolysis }(20.0 \% ; 4.127 \mathrm{e}-05) \text {, epidermis development }(13.3 \% ; 1.253 \mathrm{e}-04) \text {, ectoderm development }(13.3 \% ; 2.098 \mathrm{e}-04) \text {, organ } \\
\text { morphogenesis }(22.2 \% ; 3.330 \mathrm{e}-04) \text {, organ development }(40.0 \% ; 3.465 \mathrm{e}-04)\end{array}$ & 50 & 12 \\
\hline $\begin{array}{l}\text { Chromatin assembly }(25.5 \% ; 1.195 \mathrm{e}-17) \text {, nucleosome assembly }(23.4 \% ; 1.943 \mathrm{e}-17) \text {, chromatin assembly or disassembly } \\
(25.5 \% ; 8.776 \mathrm{e}-16) \text {, DNA packaging }(31.9 \% ; 2.566 \mathrm{e}-14) \text {, protein-DNA complex assembly }(25.5 \% ; 2.642 \mathrm{e}-14)\end{array}$ & 50 & 12 \\
\hline $\begin{array}{l}\text { Nervous system development }(34.3 \% ; 5.396 \mathrm{e}-05) \text {, DNA replication, synthesis of RNA primer }(5.7 \% ; 9.550 \mathrm{e}-05) \text {, response to } \\
\text { stress }(37.1 \% ; 1.031 \mathrm{e}-04) \text {, organ development }(45.7 \% ; 1.145 \mathrm{e}-04) \text {, lagging strand elongation }(5.7 \% ; 1.588 \mathrm{e}-04)\end{array}$ & 50 & 10 \\
\hline $\begin{array}{l}\text { Striated muscle development }(21.3 \% ; 2.853 \mathrm{e}-09) \text {, cell-substrate junction assembly }(10.6 \% ; 2.972 \mathrm{e}-09) \text {, cell adhesion } \\
(34.0 \% ; 5.859 \mathrm{e}-09) \text {, biological adhesion }(34.0 \% ; 5.859 \mathrm{e}-09) \text {, defense response }(34.0 \% ; 7.109 \mathrm{e}-09)\end{array}$ & 50 & 10 \\
\hline $\begin{array}{l}\text { Embryonic development (sensu Metazoa) }(25.5 \% ; 1.802 \mathrm{e}-10) \text {, enzyme-linked receptor protein signaling pathway } \\
(29.8 \% ; 7.648 \mathrm{e}-10) \text {, transmembrane receptor protein serine/threonine kinase signaling pathway }(19.1 \% ; 1.568 \mathrm{e}-09) \text {, transforming } \\
\text { growth factor beta receptor signaling pathway }(17.0 \% ; 2.135 \mathrm{e}-09) \text {, positive regulation of cellular process }(48.9 \% ; 1.493 \mathrm{e}-08)\end{array}$ & 50 & 9 \\
\hline $\begin{array}{l}\text { G-protein coupled receptor protein signaling pathway }(56.0 \% ; 1.989 \mathrm{e}-11) \text {, G-protein signaling, coupled to cAMP nucleotide } \\
\text { second messenger }(36.0 \% ; 5.427 \mathrm{e}-11) \text {, cAMP-mediated signaling }(36.0 \% ; 1.056 \mathrm{e}-10) \text {, second-messenger-mediated } \\
\text { signaling }(44.0 \% ; 3.660 \mathrm{e}-10) \text {, G-protein signaling, coupled to cyclic nucleotide second messenger }(36.0 \% ; 5.662 \mathrm{e}-10)\end{array}$ & 50 & 8 \\
\hline $\begin{array}{l}\text { G-protein signaling, coupled to IP3 second messenger (phospholipase C activating) }(26.7 \% ; 1.166 \mathrm{e}-09) \text {, } \\
\text { phosphoinositide-mediated signaling }(26.7 \% ; 1.010 \mathrm{e}-08) \text {, regulation of pigment cell differentiation }(10.0 \% ; 3.798 \mathrm{e}-08) \text {, } \\
\text { regulation of melanocyte differentiation }(10.0 \% ; 3.798 \mathrm{e}-08) \text {, phospholipase C activation }(16.7 \% ; 4.019 \mathrm{e}-08)\end{array}$ & 50 & 6 \\
\hline $\begin{array}{l}\text { Intracellular signaling cascade }(65.8 \% ; 3.104 \mathrm{e}-14) \text {, signal transduction }(86.8 \% ; 2.031 \mathrm{e}-13) \text {, cell communication }(89.5 \% ; 1.115 \mathrm{e}-12) \text {, } \\
\text { positive regulation of enzyme activity }(31.6 \% ; 9.101 \mathrm{e}-10) \text {, cell surface receptor linked signal transduction }(52.6 \% ; 1.514 \mathrm{e}-08)\end{array}$ & 50 & 7 \\
\hline $\begin{array}{l}\text { Glutamate signaling pathway }(21.2 \% ; 5.781 \mathrm{e}-11) \text {, metabotropic glutamate receptor signaling pathway }(15.2 \% ; 7.523 \mathrm{e}-10) \text {, } \\
\text { metabotropic glutamate receptor, phospholipase C activating pathway }(12.1 \% ; 2.649 \mathrm{e}-09) \text {, calcium ion transport }(21.2 \% ; 6.152 \mathrm{e}-08) \text {, } \\
\text { di-, tri-valent inorganic cation transport }(21.2 \% ; 2.530 \mathrm{e}-07)\end{array}$ & 50 & 7 \\
\hline $\begin{array}{l}\text { Cytoskeleton organization and biogenesis }(34.0 \% ; 9.767 \mathrm{e}-10) \text {, cellular component organization and biogenesis }(66.0 \% \text {; } \\
\text { 4.994e-09), signal transduction }(70.2 \% ; 7.124 \mathrm{e}-09) \text {, cell surface receptor linked signal transduction }(48.9 \% ; 7.831 \mathrm{e}-09) \text {, cell } \\
\text { communication }(72.3 \% ; 6.312 \mathrm{e}-08)\end{array}$ & 50 & 6 \\
\hline $\begin{array}{l}\text { Signal transduction }(78.3 \% ; 7.668 \mathrm{e}-12) \text {, cell surface receptor linked signal transduction }(56.5 \% ; 1.171 \mathrm{e}-11) \text {, cell } \\
\text { communication }(80.4 \% ; 8.686 \mathrm{e}-11) \text {, enzyme-linked receptor protein signaling pathway }(30.4 \% ; 5.553 \mathrm{e}-10) \text {, intracellular } \\
\text { signaling cascade }(50.0 \% ; 8.612 \mathrm{e}-10)\end{array}$ & 50 & 5 \\
\hline $\begin{array}{l}\text { Enzyme-linked receptor protein signaling pathway }(38.8 \% ; 2.513 \mathrm{e}-15) \text {, cell surface receptor linked signal transduction } \\
(59.2 \% ; 1.452 \mathrm{e}-13) \text {, transmembrane receptor protein tyrosine kinase signaling pathway }(30.6 \% ; 2.506 \mathrm{e}-13) \text {, signal transduction } \\
(79.6 \% ; 3.733 \mathrm{e}-13) \text {, cell communication }(83.7 \% ; 6.461 \mathrm{e}-13)\end{array}$ & 50 & 5 \\
\hline $\begin{array}{l}\text { Intracellular signaling cascade }(51.2 \% ; 2.669 \mathrm{e}-09) \text {, positive regulation of T cell activation }(14.6 \% ; 9.481 \mathrm{e}-08) \text {, positive regulation of } \\
\text { lymphocyte activation }(14.6 \% ; 2.393 \mathrm{e}-07) \text {, lymphocyte differentiation }(17.1 \% ; 3.972 \mathrm{e}-07) \text {, T cell differentiation }(14.6 \% ; 4.387 \mathrm{e}-07)\end{array}$ & 50 & 3 \\
\hline $\begin{array}{l}\text { Intracellular signaling cascade }(56.5 \% ; 1.639 \mathrm{e}-12) \text {, regulation of catalytic activity }(39.1 \% ; 2.223 \mathrm{e}-12) \text {, second-messenger- } \\
\text { mediated signaling }(34.8 \% ; 2.524 \mathrm{e}-12) \text {, regulation of a molecular function }(39.1 \% ; 5.143 \mathrm{e}-12) \text {, G-protein coupled receptor } \\
\text { protein signaling pathway }(37.0 \% ; 5.785 \mathrm{e}-10)\end{array}$ & 48 & 3 \\
\hline $\begin{array}{l}\text { Intracellular signaling cascade }(54.3 \% \text {; } 4.313 \mathrm{e}-09) \text {, second-messenger-mediated signaling }(31.4 \% ; 2.468 \mathrm{e}-08) \text {, } \\
\text { localization }(65.7 \% ; 3.153 \mathrm{e}-07) \text {, metal ion transport }(25.7 \% ; 3.468 \mathrm{e}-07) \text {, peptidyl-tyrosine phosphorylation }(17.1 \% ; 5.491 \mathrm{e}-07)\end{array}$ & 50 & 3 \\
\hline $\begin{array}{l}\text { Signal transduction }(80.9 \% ; 2.982 \mathrm{e}-13) \text {, cell surface receptor linked signal transduction }(59.6 \% ; 3.051 \mathrm{e}-13) \text {, cell differentiation } \\
(72.3 \% ; 1.869 \mathrm{e}-12) \text {, cellular developmental process }(72.3 \% ; 1.869 \mathrm{e}-12) \text {, intracellular signaling cascade }(55.3 \% ; 3.229 \mathrm{e}-12)\end{array}$ & 50 & 3 \\
\hline $\begin{array}{l}\text { Cell differentiation }(72.9 \% ; 5.953 \mathrm{e}-13) \text {, cellular developmental process }(72.9 \% ; 5.953 \mathrm{e}-13) \text {, intracellular signaling cascade } \\
(56.2 \% ; 7.116 \mathrm{e}-13) \text {, positive regulation of biological process }(60.4 \% ; 1.779 \mathrm{e}-11) \text {, regulation of apoptosis }(41.7 \% ; 2.970 \mathrm{e}-11)\end{array}$ & 50 & 2 \\
\hline
\end{tabular}

Northern blotting. ${ }^{[35]}$ A recent report suggested that $A D A M 29$ gene expression may be a strong prognostic indicator in patients with chronic lymphocytic leukemia (CML). ${ }^{[36]}$ This finding suggests that $A D A M 29$ may be expressed in other tissues in certain conditions, such as cancer cells under hypoxia in patients with CML.

To our knowledge, there have been no reports to date describing expression of the ADAM29 gene in PBMCs from patients with OSA. It is unclear whether expression of ADAM29 will be activated or if a certain proportion of cells in peripheral blood will be increased in response to the intermittent hypoxia/reoxygenation that occurs with OSA. The ADAM family gene products are involved in a highly diverse set of biological processes, including fertilization, neurogenesis, myogenesis, embryonic TGF- $\beta$ release, and inflammatory responses. ${ }^{[37]}$ The findings from several reports 
Table 4: Up- and down-regulated genes in OSA patients compared with normal control participants

\begin{tabular}{|c|c|c|c|c|}
\hline Probe set name & Gene name & Gene symbol & Unigene & Fold change \\
\hline 221337_s_at & ADAM metallopeptidase domain 29 & ADAM29 & Hs. 126838 & 7.60 \\
\hline 220573_at & Kallikrein-related peptidase 14 & KLK14 & Hs. 283925 & 3.36 \\
\hline 205389_s_at & Ankyrin 1 , erythrocytic & ANK1 & Hs. 183805 & 2.72 \\
\hline 214750_at & Placenta-specific 4 & PLAC4 & Hs. 75874 & 2.62 \\
\hline 210112_at & Hermansky-Pudlak syndrome 1 & HPS1 & Hs. 83951 & 2.56 \\
\hline 212472_at & Microtubule-associated monooxygenase, calponin and LIM domain containing 2 & $M I C A L 2$ & Hs. 198793 & 2.50 \\
\hline 206601_s_at & Homeobox D3 & HOXD3 & Hs. 93574 & 2.45 \\
\hline 203021_at & Secretory leukocyte peptidase inhibitor & SLPI & Hs. 251754 & 2.38 \\
\hline 204159_at & Cyclin-dependent kinase inhibitor 2C (p18, inhibits CDK4) & $C D K N 2 C$ & Hs. 4854 & 2.25 \\
\hline 209736_at & SRY (sex determining region Y)-box 13 & SOX13 & Hs. 201671 & 2.24 \\
\hline 208210_at & MAS1 oncogene & MAS1 & Hs. 99900 & 2.22 \\
\hline 206785_s_at & Killer cell lectin-like receptor subfamily $\mathrm{C}$, member 1 & KLRCl & Hs. 177605 & 2.19 \\
\hline 218451_at & CUB domain containing protein 1 & $C D C P 1$ & Hs. 146170 & 2.19 \\
\hline 207611_at & Histone cluster $1, \mathrm{H} 2 \mathrm{bl}$ & HIST1H2BL & Hs. 137594 & 2.19 \\
\hline 218934_s_at & Heat shock $27 \mathrm{kDa}$ protein family, member 7 (cardiovascular) & HSPB7 & Hs. 56874 & 2.18 \\
\hline 204631_at & Myosin, heavy chain 2, skeletal muscle, adult & MYH2 & Hs. 931 & 2.17 \\
\hline 212359_s_at & KIAA0913 & KIAA0913 & Hs. 65135 & 2.16 \\
\hline 207529_at & Defensin, alpha 5, Paneth cell-specific & DEFA5 & Hs. 72887 & 2.13 \\
\hline 219862_s_at & Nuclear prelamin A recognition factor & $N A R F$ & Hs. 256526 & 2.13 \\
\hline 207150_at & Solute carrier family 18 (vesicular acetylcholine), member 3 & SLC18A3 & Hs. 459 & 2.13 \\
\hline 204131_s_at & Forkhead box $\mathrm{O} 3$ & FOXO3 & Hs. 14845 & 2.12 \\
\hline 207488_at & Hs. 287545 & - & Hs. 287545 & 2.12 \\
\hline 221363_x_at & G-protein coupled receptor 25 & GPR25 & Hs. 248123 & 2.11 \\
\hline 217109_at & Mucin 4, cell surface associated & MUC4 & Hs. 198267 & 2.09 \\
\hline 204101_at & Myotubularin 1 & MTM1 & Hs. 75302 & 2.06 \\
\hline 211514_at & Receptor interacting protein kinase 5 & RIPK5 & Hs. 6874 & 2.04 \\
\hline 210140_at & Cystatin F (leukocystatin) & CST7 & Hs. 143212 & 2.04 \\
\hline 221748_s_at & Tensin 1 & TNS1 & Hs. 9973 & 2.03 \\
\hline 207384_at & Peptidoglycan recognition protein 1 & PGLYRP1 & Hs. 137583 & 2.03 \\
\hline 203691_at & Peptidase inhibitor 3, skin-derived (SKALP) & $P I 3$ & Hs. 112341 & 2.02 \\
\hline 207167_at & Immunoglobulin superfamily, member 2 & $I G S F 2$ & Hs. 74115 & 0.26 \\
\hline 207471_at & Hs. 279839 & - & Hs. 279839 & 0.31 \\
\hline 220911_s_at & KIAA1305 & KIAA1305 & Hs. 288348 & 0.37 \\
\hline 202827_s_at & Matrix metallopeptidase 14 (membrane-inserted) & MMP14 & Hs. 2399 & 0.39 \\
\hline 213631_x_at & CDNA FLJ40920 fis, clone UTERU2005905 & - & Hs. 94925 & 0.39 \\
\hline 218897_at & Transmembrane protein 177 & TMEM177 & Hs. 12199 & 0.41 \\
\hline 205774_at & Coagulation factor XII (Hageman factor) & F12 & Hs. 1321 & 0.42 \\
\hline 202627_s_at & $\begin{array}{l}\text { Serpin peptidase inhibitor, clade E (nexin, plasminogen activator inhibitor type 1), } \\
\text { member } 1\end{array}$ & SERPINE1 & Hs. 82085 & 0.43 \\
\hline 222377_at & T-box 10 & $T B X 10$ & Hs. 162247 & 0.43 \\
\hline 207337_at & Cancer/testis antigen 2 & CTAG2 & Hs. 87225 & 0.43 \\
\hline 204359_at & Fibronectin leucine-rich transmembrane protein 2 & FLRT2 & Hs. 48998 & 0.46 \\
\hline 204579_at & Fibroblast growth factor receptor 4 & FGFR4 & Hs. 165950 & 0.46 \\
\hline 209254_at & KIAA0265 protein & KIAA0265 & Hs. 192966 & 0.47 \\
\hline 220699_s_at & Hs. 283035 & - & Hs. 283035 & 0.48 \\
\hline 221142_s_at & Peroxisomal trans-2-enoyl-CoA reductase & PECR & Hs. 281680 & 0.48 \\
\hline 220447_at & Histamine receptor $\mathrm{H} 3$ & HRH3 & Hs. 251399 & 0.48 \\
\hline 208957_at & Thioredoxin domain containing 4 (endoplasmic reticulum) & TXNDC4 & Hs. 154023 & 0.49 \\
\hline 204963_at & Sarcospan (Kras oncogene-associated gene) & $S S P N$ & Hs. 183428 & 0.49 \\
\hline 205424_at & TBK1 binding protein 1 & $T B K B P 1$ & Hs. 94790 & 0.49 \\
\hline 222068_s_at & Leucine-rich repeat containing 50 & LRRC50 & Hs. 285625 & 0.49 \\
\hline 218720_x_at & Seizure-related 6 homolog (mouse)-like 2 & SEZ6L2 & Hs. 6314 & 0.49 \\
\hline 214598_at & Claudin 8 & CLDN8 & Hs. 162209 & 0.51 \\
\hline
\end{tabular}


Table 4: Contd...

\begin{tabular}{|c|c|c|c|c|}
\hline Probe set name & Gene name & Gene symbol & Unigene & Fold change \\
\hline 208031_s_at & Regulatory factor X, 2 (influences HLA class II expression) & $R F X 2$ & Hs. 100007 & 0.51 \\
\hline 209601_at & Acyl-coenzyme A oxidase 1, palmitoyl & ACOX1 & Hs. 167835 & 0.51 \\
\hline 205666_at & Flavin containing monooxygenase 1 & FMO1 & Hs. 1424 & 0.52 \\
\hline 210272_at & Cytochrome $\mathrm{P} 450$, family 2 , subfamily B, polypeptide 7 pseudogene 1 & $C Y P 2 B 7 P 1$ & Hs. 330780 & 0.53 \\
\hline 204567_s_at & ATP-binding cassette, sub-family G (WHITE), member 1 & $A B C G 1$ & Hs. 10237 & 0.53 \\
\hline 209550_at & Necdin homolog (mouse) & $N D N$ & Hs. 50130 & 0.53 \\
\hline 212023_s_at & Antigen identified by monoclonal antibody Ki-67 & MKI67 & Hs. 80976 & 0.54 \\
\hline 221883_at & PBX/knotted 1 homeobox 1 & PKNOX1 & Hs. 6700 & 0.54 \\
\hline
\end{tabular}

Abbreviations: OSA: Obstructive sleep apnea; ATP: Adenosine triphosphate; PBX: Knotted Homeobox 1

Table 5: Expression of selected genes in peripheral blood mononuclear cells from patients with OSA and normal control participants, quantified using real-time PCR

\begin{tabular}{lcc}
\hline Gene & Fold change & Fold change (GAPDH normalized) \\
\hline ADAM29 & +7.6 & +2.0 \\
CDKN2C & +2.25 & +1.25 \\
SLC18A3 & +2.13 & +1.47 \\
MMP14 & -2.56 & -2.13 \\
HSA250303 & -2.08 & -1.07 \\
FLRT2 & -2.17 & -3.1 \\
\hline
\end{tabular}

Abbreviations: OSA: Obstructive sleep apnea; PCR: Polymerase chain reaction; GAPDH: Glyceraldehyde 3 phosphate dehydrogenase

Table 6: Demographic data for participants in the validation set: Samples from these participants were used for quantitative real-time PCR

\begin{tabular}{lccc}
\hline & OSA & Control & $p$ \\
\hline Number & 25 & 24 & \\
Age (years) & $44.8 \pm 9.8$ & $32.8 \pm 11.3$ & $<0.001$ \\
Sex (M: F) & $21: 4$ & $13: 11$ & \\
BMI & $26.5 \pm 3.5$ & $21.8 \pm 2.2$ & $<0.001$ \\
RDI & $41.9 \pm 26.7$ & $0.6 \pm 0.9$ & $<0.001$ \\
\hline
\end{tabular}

Abbreviations: PCR: Polymerase chain reaction; OSA: Obstructive sleep apnea; BMI: Body mass index; RDI: Respiratory disturbance index

Table 7: Comparison between participants in the training and validation sets

\begin{tabular}{lccc}
\hline & Training set & Validation set & $p$ \\
\hline Number (OSA: Control) & $9(6: 3)$ & $49(25: 24)$ & \\
Age (years) & $52.6 \pm 14.1$ & $38.9 \pm 12.1$ & 0.016 \\
Sex (M:F) & $7: 2$ & $34: 15$ & \\
BMI & $23.7 \pm 4.4$ & $24.2 \pm 3.8$ & 0.94 \\
RDI & $37.9 \pm 36.2$ & $26.7 \pm 29.4$ & 0.22 \\
\hline
\end{tabular}

Abbreviations: OSA: Obstructive sleep apnea; BMI: Body mass index; RDI: Respiratory disturbance index

indicate that chronic inflammation occurs in patients with OSA; hence, we suggest that the existence of a chronic inflammatory status in patients with OSA may have induced the differential gene expression observed in our study. This possibility is supported by the identification of several in- flammatory pathways using MetaCore analysis, specifically TGF- $\beta$ signaling and G-protein coupled receptor signaling. Further studies are needed to elucidate the potential relationship between inflammatory pathways and ADAM29.

FLRT2 is widely expressed in human tissues, with particularly high expression levels found in ovaries and relatively high expression levels found in the brain, skeletal muscle, heart, and pancreas. ${ }^{[38]}$ Findings from a previous study indicate that FLRT2 plays a role in cell adhesion and FGF receptor signaling, and that FLRT2 contains leucine-rich repeats (LRRs), which have a diverse range of functions. ${ }^{[38]}$ LRRs provide a structural framework for the formation of protein-protein interactions, including with GTPase-activating protein rnalp, spliceosomal protein U2A', Rab geranylgeranyltransferase, internalin B, dynein light chain 1 and nuclear export protein TAP, and Skp2. ${ }^{[39]}$ We found gene transcript levels of FLRT2 were significantly depressed in patients with severe OSA compared with nonapneic control participants and patients with mild OSA. It is possible that intermittent hypoxia/reoxygenation, sleep fragmentation, or sympathetic activation resulted in disruption or inhibition of FLRT2 protein complexes, which in turn may have resulted in decreased downstream signaling in patients with severe OSA.

Vesicular acetylcholine transporter (VAChT, SLC18A3) exchanges luminal protons for cytoplasmic acetylcholine to drive the storage of acetylcholine. ${ }^{[40]}$ The distribution of SLC18A3 mRNA in the peripheral and central cholinergic nervous systems coincides with that of choline acetyltransferase (ChAT), the enzyme required for acetylcholine biosynthesis. ${ }^{[4]}$ Human SLC18A3 cDNA was used to localize the $S L C 18 A 3$ gene to chromosome 10q11.2, which is also where the ChAT gene is located. ${ }^{[41]}$ Northern blot analysis has demonstrated that this sequence is expressed in the basal forebrain, basal ganglia, and spinal cord, but not the cerebellum or peripheral tissues. In situ hybridization has demonstrated the expression of SLC18A3 mRNA in all cholinergic cell groups previously reported to express choline acetyltransferase mRNA, including those in the basal forebrain, brainstem, and spinal cord. ${ }^{[42]}$ The biological func- 


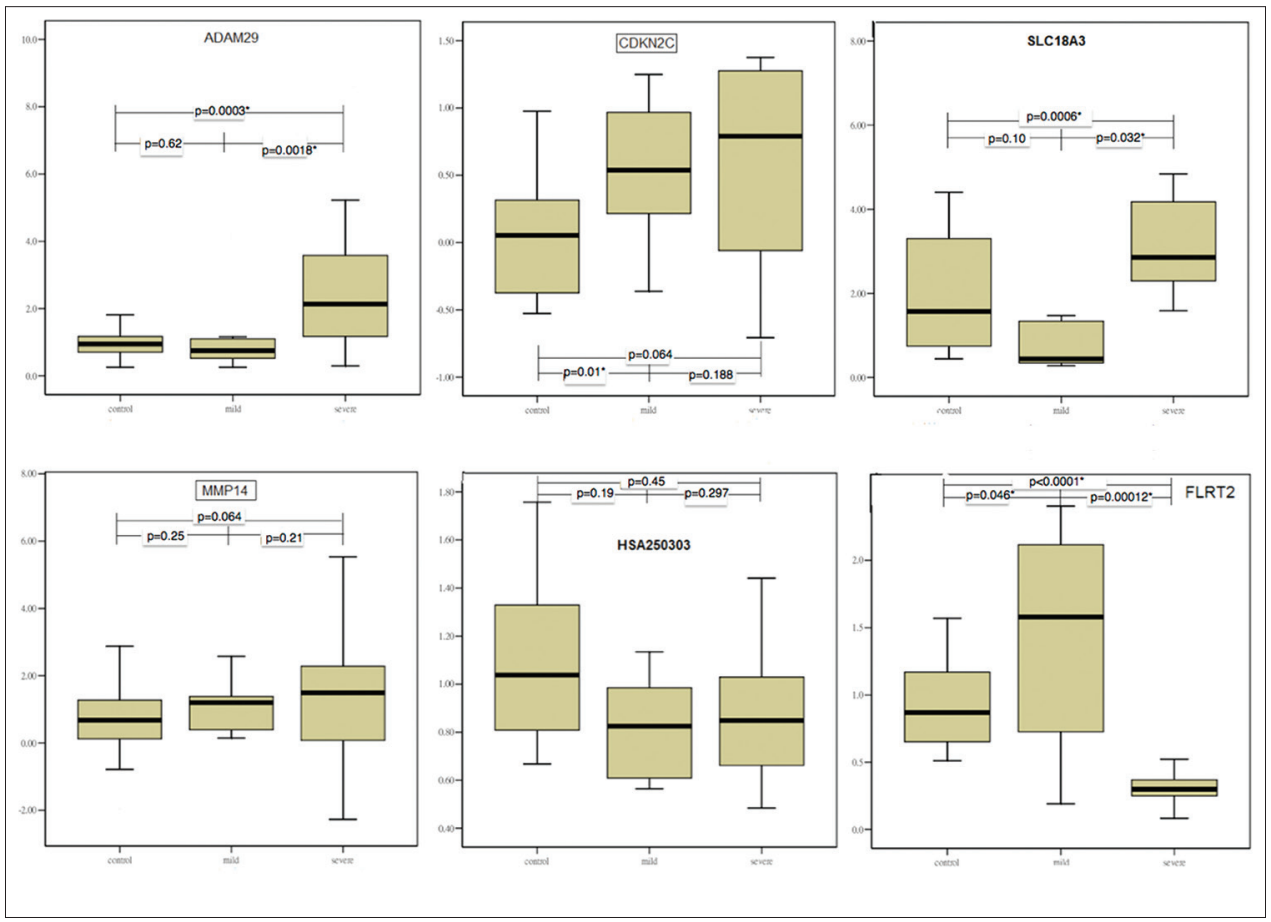

Figure 2: Expression of genes (ADAM29, CDKN2C, SLC18A3, MMP14, HSA250303, and FLRT2) in controls, and mild OSA and severe OSA subjects. The expression level of each gene was analyzed by real-time PCR and normalized by the expression level of GAPDH. * $p<0.05$

tion of $S L C 18 A 3$ remains to be determined. Our finding that SLC18A3 gene expression was significantly up-regulated in peripheral blood from patients with OSA highlights the possibility that cholinergic degeneration may be involved in mediating the impaired cognitive function in patients with OSA; however, further studies are clearly need to explore this possibility.

The protein encoded by cyclin-dependent kinase inhibitor $2 \mathrm{C}(C D K N 2 C, I N K 4 C, p 18)$ has been shown to interact with CDK4 and CDK6. Further, ectopic expression of $C D K N 2 C$ correlates with the presence of wild-type $\mathrm{Rb} 1$ and suppresses the growth of human cells. ${ }^{[43]}$ There is evidence to suggest that inactivation of $C D K N 2 C$, because of point mutations, may contribute to deregulated growth in certain cell lines and/or tumors. ${ }^{[44]}$ Using reconstituted mice with $C D K N 2 C$-deficient hematopoietic cells and in vivo evaluation of stem cell function, $C D K N 2 C$ was found to inhibit cell division in hematopoietic stem cells and early hematopoietic progenitor cells. ${ }^{[45]}$ Most of the studies conducted to date involving $C D K N 2 C$ have focused on tumor cells, but the findings from mutational analysis in sporadic pancreatic endocrine tumors argue against $C D K N 2 C$ having a tumor-suppressing function. ${ }^{[46]}$ In a previous study, transfer of $C D K N 2 C$ genes into rheumatoid arthritis synovial fibroblasts was found to suppress the production of matrix metalloproteinase- 3 and monocyte chemotactic protein- $1 .{ }^{[47]}$ These results show that cell cycle proteins play a role in regulating the expression of inflammatory mediators. In the present study, we found that $C D K N 2 C$ was differentially expressed between patients with mild OSA and control group participants; however, there was no difference in expression between patients with severe OSA and the control group participants. This discordance is a reflection of the widely distributed data in the group of patients with severe OSA. Therefore, we plan to collect additional samples to further compare the expression of $C D K N 2 C$ between patients with OSA and nonapneic control participants.

A previous study used HG-U133A and B arrays (Affymetrix) to analyze genomic oxidative stress and cell cycle responses in peripheral blood from adults with OSA. ${ }^{[28]}$ The authors of the study found that there were significant changes in the expression of several genes involved in modulation of ROS, cell growth, proliferation, and the cell cycle (e.g., cell division cycle 25B, signaling lymphocyte activating molecule, calgizzarin S100A11, B-cell translocation gene, Src-like adapter protein, and eukaryotic translation initiation factor $4 \mathrm{E}$ binding protein 2). ${ }^{[28]}$ These results are different from ours, perhaps reflecting differences in race/ethnicity. Our patients with OSA had lower BMI ( $26.9 \pm 4.2$ vs. $35.5 \pm 1.29)$, despite having similar RDI severity $(42.9 \pm 28.9$ vs. $50.2 \pm 23.5)$. Differences in race may have resulted in different gene expression profiles in the peripheral blood obtained from patients with OSA. In another study, gene expression profiling in non-obese 
children with OSA was also performed using microarray. ${ }^{[29]}$ The authors identified significant changes in three genes, malonyl-CoA and a mitochondrial acyl carrier protein, serine 36 protease, and interleukin 27. The findings from this study are different from the aforementioned findings ${ }^{[28]}$ and, indeed, our own findings. This may be because the majority of pediatric patients with OSA have adenoid/tonsillar hypertrophy, whereas the population of adults with OSA is heterogenous. The etiology of pediatric and adult OSA is different; hence, it is difficult to compare microarray results, even if the same microarray platform is used.

Our study has two limitations that warrant mention. The first limitation concerns the control of sex and BMI. Participants enrolled in the training and validation sets were not sex- or BMI-matched; hence, the observed differential expression of our candidate genes may have been confounded to some extent by sex and obesity. The second limitation concerns the generalizablity of our findings. We suggest that our findings may not be broadly generalizable because of the limited number of individuals included in the study.

In summary, we have used microarray analysis to search for genes potentially involved in the pathogenesis of OSA. We detected changes in gene patterns in PBMCs obtained from patients with severe OSA as compared with normal control participants and patients with mild OSA. Patients with severe OSA may have a higher risk of developing cardiovascular disease or stroke; hence, aggressive treatment or intensive care may be warranted. Early diagnosis and aggressive treatment will help prevent disease progression. We identified potential markers of OSA in a small Asian population. These markers may be useful to routinely screen individuals and identify those at risk of severe OSA. Further study of these markers and their potential applicability for the screening of OSA is warranted in larger populations.

\section{ACKNOWLEDGMENT}

This study was supported by grants from the Chang Gung Medical Research Fund (CMRPG350011 and CMRPG361171).

\section{REFERENCES}

1. American Thoracic Society. Indications and standards for use of nasal continuous positive airway pressure (CPAP) in sleep apnea syndromes. Am J Respir Crit Care Med 1994;150:1738-45.

2. Young T, Peppard PE, Gottlieb DJ. Epidemiology of obstructive sleep apnea: A population health perspective. Am J Respir Crit Care Med 2002;165:1217-39.

3. Stoohs R, Guilleminault C. Cardiovascular changes associated with obstructive sleep apnea syndrome. J Appl Physiol 1992;72:583-9.

4. Hung J, Whitford EG, Parsons RW, Hillman DR. Association of sleep apnoea with myocardial infarction in men. Lancet 1990;336:261-4.

5. Hajak G, Klingelhofer J, Schulz-Varszegi M, Sander D, Ruther E. Sleep apnea syndrome and cerebral hemodynamics. Chest 1996;110:670-9.

6. Grunstein RR, Stenlof K, Hedner J, Sjostrom L. Impact of obstructive sleep apnea and sleepiness on metabolic and cardiovascular risk factors in the Swedish Obese Participants (SOS) Study. Int J Obes Relat Metab Disord 1995;19:410-8.

7. Grote L, Ploch T, Heitmann J, Knaack L, Penzel T, Peter JH. Sleep-related breathing disorder is an independent risk factor for systemic hypertension. Am J Respir Crit Care Med 1999;160:1875-82.

8. Findley LJ, Unverzagt ME, Suratt PM. Automobile accidents involving patients with obstructive sleep apnea. Am Rev Respir Dis 1988;138:337-40.

9. Kales A, Caldwell AB, Cadieux RJ, Vela-Bueno A, Ruch LG, Mayes SD. Severe obstructive sleep-apnea-II: Associated psychopathology and psychosocial consequences. J Chronic Dis 1985;38:427-34.

10. D'Ambrosio C, Bowman T, Mohsenin V. Quality of life in patients with obstructive sleep apnea: Effect of nasal continuous positive airway pressure-a prospective study. Chest 1999;115:123-9.

11. Sleep-related breathing disorders in adults: Recommendations for syndrome definition and measurement techniques in clinical research. The Report of an American Academy of Sleep Medicine Task Force. Sleep 1999;22:667-89.

12. American Academy of Sleep Medicine. The International Classification of Sleep Disorders, $2^{\text {nd }}$ ed, diagnostic and coding manual. Westchester: American Academy of Sleep Medicine; 2005.

13. Young T, Shahar E, Nieto FJ, Redline S, Newman AB, Gottlieb DJ, et al. Sleep Heart Health Study Research Group. Predictors of sleep-disordered breathing in community-dwelling adults: The Sleep Heart Health Study. Arch Intern Med 2002;162:893-900.

14. Tishler PV, Larkin EK, Schluchter MD, Redline S. Incidence of sleep-disordered breathing in an urban adult population: The relative importance of risk factors in the development of sleep-disordered breathing. JAMA 2003;289:2230-7.

15. Scanlan MF, Roebuck T, Little PJ, Redman JR, Naughton MT. Effect of moderate alcohol upon obstructive sleep apnoea. Eur Respir J 2000;16:909-13.

16. Kripke DF, Ancoli-Israel S, Klauber MR, Wingard DL, Mason WJ, Mullaney DJ. Prevalence of sleep-disordered breathing in ages 40-64 years: A population-based survey. Sleep 1997;20:65-76.

17. Redline S, Tishler PV, Hans MG, Tosteson TD, Strohl KP, Spry K. Racial differences in sleep-disordered breathing in African-Americans and Caucasians. Am J Respir Crit Care Med 1997;155:186-92.

18. Ip Mary SM, Tsang WT, Lam WK, Lam B. Obstructive sleep apnea syndrome: An experience in Chinese adults in Hong Kong. Chin Med J (Engl) 1998;111:257-60.

19. Li KK, Kushida C, Powell NB, Riley RW, Guilleminault C. Obstructive sleep apnea syndrome: A comparison between Far-East Asian and white men. Laryngoscope 2000;110:1689-93.

20. Li KK, Powell NB, Kushida C, Riley RW, Adornato B, Guilleminault C. A comparison of Asian and white patients with obstructive sleep apnea syndrome. Laryngoscope 1999;109:1937-40.

21. Yokoe T, Minoguchi K, Matsuo H, Oda N, Minoguchi H, Yoshino G, et al. Elevated levels of C-reactive protein and interleukin-6 in patients with obstructive sleep apnea syndrome are decreased by nasal 
continuous positive airway pressure. Circulation 2003;107:1129-34.

22. Minoguchi K, Tazaki T, Yokoe T, Minoguchi H, Watanabe Y, Yamamoto $\mathrm{M}$, et al. Elevated production of tumor necrosis factor-alpha by monocytes in patients with obstructive sleep apnea syndrome. Chest 2004;126:1473-9.

23. Leung RS, Bradley TD. Sleep apnea and cardiovascular disease. Am J Respir Crit Care Med 2001;164:2147-65.

24. El Solh AA, Akinnusi ME, Baddoura FH, Mankowski CR. Endothelial cell apoptosis in obstructive sleep apnea: A link to endothelial dysfunction. Am J Respir Crit Care Med 2007;175:1186-91.

25. Ryan S, Taylor CT, McNicholas WT. Selective activation of inflammatory pathways by intermittent hypoxia in obstructive sleep apnea syndrome. Circulation 2005;112:2660-7.

26. McNicholas WT, Ryan S. Obstructive sleep apnoea syndrome: Translating science to clinical practice. Respirology 2006;11:136-44.

27. Ohga E, Nagase T, Tomita T, Teramoto S, Matsuse T, Katayama H, et al. Increased levels of circulating ICAM-1, VCAM-1, and L-selectin in obstructive sleep apnea syndrome. J Appl Physiol 1999;87:10-4.

28. Hoffmann MS, Singh P, Wolk R, Romero-Corral A, Raghavakaimal S, Somers VK. Microarray studies of genomic oxidative stress and cell cycle responses in obstructive sleep apnea. Antioxid Redox Signal 2007;9:661-9.

29. Khalyfa A, Capdevila OS, Buazza MO, Serpero LD, Kheirandish-Gozal L, Gozal D. Genome-wide gene expression profiling in children with non-obese obstructive sleep apnea. Sleep Med 2009;10:75-86.

30. Bolstad BM, Irizarry RA, Astrand M, Speed TP. A comparison of normalization methods for high density oligonucleotide array data based on variance and bias. Bioinformatics 2003;19:185-93.

31. de Hoon MJ, Imoto S, Nolan J, Miyano S. Open source clustering software. Bioinformatics 2004;20:1453-4

32. Nikolsky Y, Ekins S, Nikolskaya T, Bugrim A. A novel method for generation of signature networks as biomarkers from complex high throughput data. Toxicol Lett 2005;158:20-9.

33. Mason CW, Swaan PW, Weiner CP. Identification of interactive gene networks: A novel approach in gene array profiling of myometrial events during guinea pig pregnancy. Am J Obstet Gynecol 2006;194:1513-23.

34. Feezor RJ, Baker HV, Mindrinos M, Hayden D, Tannahill CL, Brownstein $\mathrm{BH}$, et al. Whole blood and leukocyte RNA isolation for gene expression analyses. Physiol Genomics 2004;19:247-54.

35. Xu R, Cai J, Xu T, Zhou W, Ying B, Deng K, et al. Molecular cloning and mapping of a novel ADAM gene (ADAM29) to human chromosome 4. Genomics 1999;62:537-9.

36. Oppezzo P, Vasconcelos Y, Settegrana C, Jeannel D, Vuillier F, Legarff-Tavernier M, et al. The LPL/ADAM29 expression ratio is a novel prognosis indicator in chronic lymphocytic leukemia. Blood 2005;106:650-7.

37. Primakoff P, Myles DG. The ADAM gene family: Surface proteins with adhesion and protease activity. Trends Genet 2000;16:83-7.

38. Lacy SE, Bonnemann CG, Buzney EA, Kunkel LM. Identification of FLRT1, FLRT2, and FLRT3: A novel family of transmembrane leucine-rich repeat proteins. Genomics 1999;62:417-26.

39. Kobe B, Kajava AV. The leucine-rich repeat as a protein recognition motif. Curr Opin Struct Biol 2001;11:725-32.

40. Bahr BA, Clarkson ED, Rogers GA, Noremberg K, Parsons SM. A kinetic and allosteric model for the acetylcholine transporter-vesamicol receptor in synaptic vesicles. Biochemistry 1992;31:5752-62.

41. Erickson JD, Varoqui H, Schafer MK, Modi W, Diebler MF, Weihe E, et al. Functional identification of a vesicular acetylcholine transporter and its expression from a „cholinergic" gene locus. J Biol Chem 1994;269:21929-32

42. Roghani A, Feldman J, Kohan SA, Shirzadi A, Gundersen CB Brecha $\mathrm{N}$, et al. Molecular cloning of a putative vesicular transporter for acetylcholine. Proc Natl Acad Sci U S A 1994;91:10620-4

43. Guan KL, Jenkins CW, Li Y, Nichols MA, Wu X, O'Keefe CL, et al. Growth suppression by $\mathrm{p} 18$, a p16INK4/MTS1- and p14INK4B/ MTS2-related CDK6 inhibitor, correlates with wild-type $\mathrm{pRb}$ function. Genes Dev 1994;8:2939-52

44. Lapointe J, Lachance Y, Labrie Y, Labrie C. A p18 mutant defective in CDK6 binding in human breast cancer cells. Cancer Res $1996 ; 56: 4586-9$

45. Yuan Y, Shen H, Franklin DS, Scadden DT, Cheng T. In vivo self-renewing divisions of haematopoietic stem cells are increased in the absence of the early G1-phase inhibitor, p18INK4C. Nat Cell Biol 2004;6:436-42.

46. Lindberg D, Akerstrom G, Westin G. Mutational analysis of p27 (CDKN1B) and p18 (CDKN2C) in sporadic pancreatic endocrine tumors argues against tumor-suppressor function. Neoplasia 2007;9:533-5.

47. Nonomura Y, Nagasaka K, Hagiyama H, Sekine C, Nanki T, Tamamori-Adachi M, et al. Direct modulation of rheumatoid inflammatory mediator expression in retinoblastoma protein-dependent and -independent pathways by cyclin-dependent kinase 4/6. Arthritis Rheum 2006:54:2074-83. 